\title{
Various factors affect erythrocyte blood transfusions in hip fracture patients
}

\author{
M. Eghbal Heidari ${ }^{1}$
}

Received: 28 July 2018 / Accepted: 30 July 2018 / Published online: 14 August 2018

○) Springer-Verlag France SAS, part of Springer Nature 2018

Dear editor,

We studied Smeets et al.'s valuable article [1], entitled "Effect of blood transfusion on survival after hip fracture surgery" published in European Journal of Orthopaedic Surgery and Traumatology (2018), and enjoyed it. Consequently, it is useful and important in healthcare system. In this retrospective cohort study that was conducted in the Maastricht University Medical Center in the Netherlands, the 388 included patients were 65 years old and above and treated operatively for an acute hip fracture with a 2-year follow-up period. In this study, it is noted that the postoperative hemoglobin level was the strongest predictor for erythrocyte blood transfusions. Transfusion was associated with a longer hospital stay. There were significantly more extracapsular fractures in the transfused group. After reviewing the statistical results, there was no effect of erythrocyte blood transfusions on mortality. But in a retrospective study [2] by fractures done on 84 patients with femoral shaft fractures whom were operated in Imam Khomeini Hospital in Sari, in northern Iran, during 2012-2015 there was a significant relationship between the blood transfusion and the sex of the patients that is consistent with the results of the studies by Kajja et al. and Kadar et al. However, there was not a significant relationship between the amount of blood transfusion and the age of the patients as well as the length of hospitalization. In this study, unlike Smeets et al.'s study, there was a significant relationship between blood transfusion and preoperative hemoglobin of the patients. Thus, the most important factor in determining the need for blood transfusion is the amount of preoperative blood loss that is detected with preoperative hemoglobin. Also, in this study, there was a significant relationship between the fracture energy intensity and the amount of blood transfusion. This study recommended for hip fracture at least three units of blood should be reserved. According to the results of these studies, therefore, we should consider the various factors in erythrocyte blood transfusions in these patients.

\section{Compliance with ethical standards}

Conflict of interest The author declares that he has no conflict of interest for this study.

\section{References}

1. Ghaffari S, Shayesteh AM, Kariminasab M, Daneshpoor S, Anoosheh M, Ghaffari B (2017) Blood loss and need for transfusion assessment in open reduction and internal fixation of femoral shaft fractures. J Gorgan Univ Med Sci 19(1):72-76

2. Smeets S, Verbruggen J, Poeze M (2018) Effect of blood transfusion on survival after hip fracture surgery. Eur J Orthop Surg Traumatol. https://doi.org/10.1007/s00590-018-2205-z
M. Eghbal Heidari

mohammad.eghbal.heydari@gmail.com

1 Scientific Research Center, Faculty of Nursing Midwifery, Tehran University of Medical Sciences, Tehran, Iran 